\title{
The timing of venous thromboembolic events after spine surgery: a single-center experience with 6869 consecutive patients
}

\author{
Presented at the 2017 AANS/CNS Joint Section on Disorders of the Spine and Peripheral Nerves \\ Michael B. Cloney, MD, MPH, ${ }^{1}$ Benjamin Hopkins, BSc, ${ }^{2}$ Ekamjeet S. Dhillon, BSc, ${ }^{2}$ and \\ Nader S. Dahdaleh, MD'
} 'Department of Neurological Surgery, Feinberg School of Medicine, and ${ }^{2}$ Feinberg School of Medicine, Northwestern University,
Chicago, Illinois

\begin{abstract}
OBJECTIVE Venous thromboembolic events (VTEs), including both deep venous thrombosis (DVT) and pulmonary embolism, are a major cause of morbidity and mortality after spine surgery. Prophylactic anticoagulation, or chemoprophylaxis, can prevent VTE. However, the timing of VTEs after spine surgery and the effect of chemoprophylaxis on VTE timing remain underinvestigated.
\end{abstract}

METHODS The records of 6869 consecutive spine surgeries were retrospectively examined. Data on patient demographics, surgical variables, hospital course, and timing of VTEs were collected. Patients who received chemoprophylaxis were compared with those who did not. Appropriate regression models were used to examine selection for chemoprophylaxis and the timing of VTEs.

RESULTS Age (OR 1.037, 95\% Cl 1.023-1.051; $p<0.001)$, longer surgery (OR 1.003, 95\% Cl 1.002-1.004; $p<0.001)$, history of DVT (OR 1.697, 95\% Cl 1.038-2.776; $p=0.035)$, and fusion surgery (OR 1.917, 95\% Cl 1.356-2.709; $p<$ $0.001)$ predicted selection for chemoprophylaxis. Chemoprophylaxis patients experienced more VTEs $(3.62 \%$ vs $2.03 \%$ of patients, respectively; $p<0.001$ ), and also required longer hospital stays (5.0 days vs 1.0 days; HR $0.5107 ; p<0.0001)$ and had a greater time to the occurrence of VTE (median 6.8 days vs 3.6 days; HR $0.6847 ; p=0.0003$ ). The cumulative incidence of VTEs correlated with the postoperative day in both groups (Spearman $r=0.9746,95 \% \mathrm{Cl} 0.9457-0.9883$, and $p<0.0001$ for the chemoprophylaxis group; Spearman $r=0.9061,95 \% \mathrm{Cl} 0.8065-0.9557$, and $p<0.0001$ for the nonchemoprophylaxis group), and the cumulative incidence of VTEs was higher in the nonchemoprophylaxis group throughout the 30-day postoperative period. Cumulative VTE incidence and postoperative day were linearly correlated in the first 2 postoperative weeks $(R=0.9396$ and $p<0.0001$ for the chemoprophylaxis group; $R=0.8190$ and $p=0.0003$ for the nonchemoprophylaxis group) and the remainder of the 30-day postoperative period $(R=0.9535$ and $p<0.0001$ for the chemoprophylaxis group; $R=0.6562$ and $p=0.0058$ for the nonchemoprophylaxis group), but the linear relationships differ between these 2 postoperative periods ( $p<0.0001$ for both groups).

CONCLUSIONS Anticoagulation reduces the cumulative incidence of VTE after spine surgery. The cumulative incidence of VTEs rises linearly in the first 2 postoperative weeks and then plateaus. Surgeons should consider early initiation of chemoprophylaxis for patients undergoing spine surgery.

https://thejns.org/doi/abs/10.3171/2017.5.SPINE161399

KEY WORDS venous thromboembolism; pulmonary embolism; deep vein thrombosis; spine surgery; chemoprophylaxis; anticoagulation; DVT; vascular disorders

ABBREVIATIONS BMI = body mass index; CPT= Current Procedural Terminology; DVT = deep venous thrombosis; EBL = estimated blood loss; VTE = venous thromboembolic event.

SUBMITTED December 11, 2016. ACCEPTED May 22, 2017.

INCLUDE WHEN CITING Published online November 10, 2017; DOI: 10.3171/2017.5.SPINE161399. 
$\mathrm{V}$ ENOus thromboembolic events (VTEs), including deep venous thrombosis (DVT) and pulmonary embolism, are major postoperative complications. ${ }^{5,6,14,18,22,23}$ Patients undergoing major surgery, including spine surgery, are at increased risk of VTE.,3,25 The annual number of spine surgeries performed in the United States is growing rapidly. ${ }^{7,8,13}$ As such, it is critical to define the appropriate management to prevent VTEs in patients undergoing spine surgery.

Protocols for the use of chemoprophylactic anticoagulation are well established for some surgeries, most notably hip and knee arthroplasty. ${ }^{26,28,30}$ However, evidence for the appropriate use of chemoprophylactic anticoagulation after spine surgery is less robust, ${ }^{10}$ and clear evidence-based guidelines are lacking. ${ }^{8}$ Existing studies have identified a variety of risk factors for VTEs after spine surgery, 3,4 , 15,28 but patient selection remains a significant hindrance to the interpretation of these results, likely contributing to the wide variability in the use of chemoprophylaxis in this population..$^{10}$ Furthermore, the timing of VTEs after spine surgery and the effect of chemoprophylaxis on VTE timing remain underexamined. In this study, we examine patient selection for chemoprophylactic anticoagulation after spine surgery, the occurrence and timing of VTEs after spine surgery, and the timing and effect of chemoprophylactic anticoagulation on those outcomes.

\section{Methods \\ Data Source}

All patients who underwent spine surgery at the Departments of Neurological Surgery and Orthopedic Surgery at our institution between January 1, 2009, and May 31, 2015, were identified using the Northwestern University Electronic Data Warehouse. The Electronic Data Warehouse is a clinical data repository jointly funded by Northwestern Memorial Hospital, Northwestern Medical Faculty Foundation, and Northwestern University Feinberg School of Medicine. Spine surgeries were identified using Current Procedural Terminology (CPT) codes, and all identified primary spine surgeries were included in the analysis. Minor procedures (including electrode placements or hardware removal) and secondary procedures (operations for wound dehiscence and hematoma evacuations) were not included as cases. Microdiscectomy and minimally invasive surgery procedures were included as major index cases. For each spine surgery included in the study, data were collected about the patient, procedure, and postoperative management and recovery. The study was approved by the institutional review board.

\section{Patient Data}

We collected the following patient data: age at surgery, sex, body mass index (BMI), smoking status (never, current, or quit $<1$ year prior), race (Caucasian, African American, Hispanic, Pacific Islander, or other), history of VTEs, history of bleeding disorders, and number of comorbidities present (hypertension, cardiac, renal, pulmonary, diabetes, and other endocrine disease), as identified by the ninth edition of International Classification of Disease codes.

\section{Procedure Data}

We collected the following data about the procedures performed: prophylactic inferior vena cava filter placement, site of surgery (cervical, thoracic, lumbar, other), whether a fusion was part of the procedure, whether decompressions (laminectomy, laminotomy) were a part of the procedure, length of surgery (minutes), estimated blood loss (EBL) in milliliters, use of transfusion, intensive care unit admission, and length of hospitalization (days).

\section{Chemoprophylaxis Data}

We collected data on the use of chemoprophylactic anticoagulation in our patients. Given recent data showing that spine surgeons who administer chemoprophylactic anticoagulation do so in the first few days following surgery, ${ }^{15}$ we defined chemoprophylaxis as anticoagulation given from 1 day prior to the operation to 3 days postoperatively. We considered any patient receiving $5000 \mathrm{U}$ heparin, $40 \mathrm{mg}$ enoxaparin, 2500 or $5000 \mathrm{U}$ dalteparin, or $2.5 \mathrm{mg}$ fondaparinux from 1 day prior to operation to 3 days postoperatively to be receiving these medications prophylactically (Table 1). Patients receiving higher doses of these anticoagulants, as well as patients receiving aspirin or warfarin, were not considered to be receiving these medications prophylactically. Patients receiving anticoagulant therapy from 1 day prior to operation to 3 days postoperatively (chemoprophylaxis group; $\mathrm{n}=1904$ [27.7\%]) were compared with the remaining patients (nonchemoprophylaxis group; $n=4965$ [72.3\%]). The incidence of VTEs and spinal epidural hematomas were compared between these groups. Lower-extremity duplex scans were routinely obtained on postoperative Day 1 for patients whose providers considered them to be high risk.

\section{Outcomes Data}

Data were collected on the occurrence and timing of VTEs (defined as either DVT or pulmonary embolism) and epidural hematomas within the 30-day postoperative period. Given likely selection biases in distinguishing patients receiving chemoprophylaxis from those who did not, including more complex surgeries requiring prolonged hospitalization and immobilization, a cumulative incidence of the VTEs was calculated for each postoperative day within the 30-day postoperative period. The $\mathrm{cu}-$ mulative incidence of VTEs for a given postoperative day was defined as follows: (cumulative incidence of VTEs) = (VTEs)/(total patient-days).

All inpatients were included for the purposes of calculating at-risk patients when counting total patient-days.

TABLE 1. Types of anticoagulation therapy used for chemoprophylaxis

\begin{tabular}{ccc}
\hline Type of Anticoagulant & Dose & No. of Patients (\%) \\
\hline Heparin & $5000 \mathrm{U}$ & $239(42.28)$ \\
\hline Enoxaparin & $40 \mathrm{mg}$ & $431(22.64)$ \\
\hline Dalteparin & $2500 \mathrm{U}$ & $2(0.11)$ \\
& $5000 \mathrm{U}$ & $663(34.82)$ \\
\hline Fondaparinux & $2.5 \mathrm{mg}$ & $3(0.16)$ \\
\hline
\end{tabular}


We also identified patients who received venous duplex ultrasounds within 30 days after surgery using specific CPT codes; however, we are unable to determine whether those scans were used for screening purposes or because of DVT symptoms due to variability in provider practice.

\section{Statistical Methods}

Microsoft Excel 2011 was used for data management, and Stata 12.0 (StataCorp) and Prism 6.0b (GraphPad Software, Inc.) were used to conduct all statistical analyses. Parametric data are given as the mean \pm standard deviation and were compared using the Student t-test, and nonparametric data were compared using the Mann-Whitney U-test or chi-square test, as appropriate. Time-to-event data were analyzed using Mantel-Cox statistics. Comparisons between linear regression lines were performed using analysis of covariance, as described elsewhere. ${ }^{29} \mathrm{Re}-$ gression analysis was performed using logistic regression, and candidate variables with $\mathrm{p}<0.10$ on single-variable logistic regression were included in the multivariable logistic regression. A $p$ value $<0.05$ was considered statistically significant.

\section{Results}

A total of 6869 procedures met the study inclusion criteria. Compared with the nonchemoprophylaxis group $(\mathrm{n}=4965)$, patients in the chemoprophylaxis group ( $\mathrm{n}=$ 1904) were older, had more comorbid diagnoses and higher BMIs, and were more likely to be female and have a history of VTE, a history of bleeding disorders, and neurological deficits (Table 2). With respect to the procedure characteristics, patients receiving chemoprophylaxis were more likely to have had thoracic surgery, fusions, staged surgeries, longer surgeries, longer anesthesia time, greater EBL, and greater transfusion volume and more likely to require transfusion (Table 3). On multivariable analysis, age (OR 1.037, 95\% CI 1.022-1.051; $\mathrm{p}<0.001)$, length of surgery (OR 1.003, 95\% CI 1.002-1.004; $\mathrm{p}<0.001$ ), previous history of DVT (OR 1.697, 95\% CI 1.038-2.776; $\mathrm{p}=$ 0.035 ), and fusion surgery (OR 1.917, 95\% CI 1.356-2.709; $\mathrm{p}<0.001)$ all predicted selection for chemoprophylactic anticoagulation (Table 4). The median time of initiation of chemoprophylaxis was postoperative Day 1.46.

The rates of epidural hematoma were the same in the chemoprophylaxis group and nonchemoprophylaxis group

TABLE 2. Patient characteristics at baseline in the chemoprophylaxis and nonchemoprophylaxis groups

\begin{tabular}{|c|c|c|c|}
\hline Variable & Nonchemoprophylaxis Group & Chemoprophylaxis Group & p Value \\
\hline No. of patients & 4965 & 1904 & \\
\hline Age, mean $\pm S D, y r s$ & $51.86 \pm 15.45$ & $59.70 \pm 14.41$ & $<0.001$ \\
\hline $95 \% \mathrm{Cl}$ & $51.43-52.29$ & $59.05-60.35$ & \\
\hline Median & 52 & 62 & $<0.001$ \\
\hline Sex & & & $<0.001$ \\
\hline Male & $2774(56)$ & $902(47)$ & \\
\hline Female & $2191(44)$ & $1002(53)$ & \\
\hline $\mathrm{BMl}$, mean $\pm \mathrm{SD}$ & $28.11 \pm 5.96$ & $29.31 \pm 6.83$ & $<0.001$ \\
\hline $95 \% \mathrm{Cl}$ & $27.95-28.28$ & $29.00-29.62$ & \\
\hline Median & 27.21 & 27.98 & $<0.001$ \\
\hline Smoking status & & & $<0.001$ \\
\hline Never & $4159(84)$ & $1621(85)$ & \\
\hline Current & $734(15)$ & $221(12)$ & \\
\hline Quit <1 yr prior & $67(1)$ & $57(3)$ & \\
\hline Race & & & 0.04 \\
\hline Caucasian & $3450(69)$ & $1305(69)$ & \\
\hline African American & $437(9)$ & $213(11)$ & \\
\hline Hispanic & $275(6)$ & $96(5)$ & \\
\hline Pacific Islander & $12(0.24)$ & $5(0.26)$ & \\
\hline Other & $791(16)$ & $285(15)$ & \\
\hline VTE history & $104(2.1)$ & $111(5.8)$ & $<0.001$ \\
\hline Epidural hematoma history & $1(0.07)$ & $1(0.13)$ & 0.4 \\
\hline Bleeding disorder history & $31(2.2)$ & $28(3.6)$ & $<0.001$ \\
\hline Neurological deficit & $60(4)$ & $44(6)$ & 0.004 \\
\hline \multicolumn{4}{|l|}{ No. of comorbidities } \\
\hline Mean \pm SD & $1.89 \pm 1.48$ & $2.69 \pm 1.35$ & $<0.001$ \\
\hline $95 \% \mathrm{Cl}$ & $1.85-1.93$ & $2.63-2.75$ & \\
\hline Median & 2 & 3 & $<0.001$ \\
\hline
\end{tabular}

Values are presented as the number of patients (\%) unless specified otherwise. 
TABLE 3. Procedure characteristics of the chemoprophylaxis and nonchemoprophylaxis groups

\begin{tabular}{|c|c|c|c|}
\hline Characteristic & Nonchemoprophylaxis Group & Chemoprophylaxis Group & p Value \\
\hline Timing of anticoagulant, days & NA & 1.46 & \\
\hline Inferior vena cava filter placed & $96(1.93)$ & $163(8.56)$ & $<0.001$ \\
\hline Site of surgery & & & $<0.001$ \\
\hline Cervical & $1313(26.5)$ & $461(24.2)$ & \\
\hline Thoracic & $184(3.71)$ & $213(11.2)$ & \\
\hline Lumbar & $3442(69.3)$ & $1196(62.8)$ & \\
\hline Other & $27(0.54)$ & $34(1.79)$ & \\
\hline Fusion & $1225(24.7)$ & $878(46.1)$ & $<0.001$ \\
\hline Decompression & $1664(33.5)$ & $710(37.3)$ & $<0.001$ \\
\hline Staged surgeries & $85(44.3)$ & $100(62.50)$ & 0.013 \\
\hline Surgery time, mean $\pm S D$, mins & $145.56 \pm 127.12$ & $278.59 \pm 181.81$ & $<0.001$ \\
\hline $95 \% \mathrm{Cl}$ & $142.02-149.10$ & $270.42-286.76$ & \\
\hline Median & 108 & 228 & $<0.001$ \\
\hline Anesthesia time, mean \pm SD, mins & $204.94 \pm 145.26$ & $363.05 \pm 201.89$ & $<0.001$ \\
\hline $95 \% \mathrm{Cl}$ & $200.90-208.98$ & $353.98-372.13$ & \\
\hline Median & 164 & 309 & $<0.001$ \\
\hline $\mathrm{EBL}$, mean $\pm \mathrm{SD}, \mathrm{ml}$ & $447.98 \pm 1383.62$ & $994.77 \pm 1549.99$ & $<0.001$ \\
\hline $95 \% \mathrm{Cl}$ & $381.45-514.51$ & $902.48-1087.06$ & \\
\hline Median & 75 & 400 & $<0.001$ \\
\hline Red blood cells, mean \pm SD, $\mathrm{ml}$ & $1476.04 \pm 1805.34$ & $1315.38 \pm 1262.27$ & 0.004 \\
\hline $95 \% \mathrm{Cl}$ & $1256.84-1695.24$ & 1199.35-1431.42 & \\
\hline Median & 800 & 900 & 0.721 \\
\hline ICU admission & $518(10.4)$ & $751(39.4)$ & $<0.001$ \\
\hline Length of stay, median, days & 1 & 5 & $<0.001$ \\
\hline $\mathrm{HR}$ & 1.958 & 0.5107 & \\
\hline $95 \% \mathrm{Cl}$ & $2.589-2.849$ & $0.3510-0.3862$ & \\
\hline
\end{tabular}

NA = not applicable.

Values are presented as the number of patients (\%) unless specified otherwise.

(4 patients [0.2\%] vs 9 patients [0.2\%]; $\mathrm{p}=0.619)$. The timing of epidural hematoma development did not differ between the chemoprophylaxis group and nonchemoprophylaxis group (10.84 days vs 6.2 days; HR $0.8569,95 \%$ CI $0.2550-2.893$; $\log$-rank $\mathrm{p}=0.8061$ ).

The rates of pulmonary embolism were the same in the chemoprophylaxis group and the nonchemoprophylaxis group (15 patients [0.60\%] vs 30 patients [0.80\%]; $\mathrm{p}=$ 0.090). However, chemoprophylaxis patients experienced more VTEs overall $(3.62 \%$ vs $2.03 \%$; $p<0.001)$. Notably, patients receiving chemoprophylaxis also had longer hospital stays (5.0 days vs 1.0 days; HR 0.5107 , log-rank $\mathrm{p}<0.0001)$ and delayed time to the occurrence of VTEs

TABLE 4. Predictors of chemoprophylaxis

\begin{tabular}{lccc}
\hline \multicolumn{1}{c}{ Variable } & $\mathrm{p}$ Value & OR & $95 \% \mathrm{Cl}$ \\
\hline Op time & $<0.001$ & 1.003 & $1.002-1.004$ \\
\hline Age & $<0.001$ & 1.037 & $1.023-1.051$ \\
\hline Stenosis & 0.003 & 0.598 & $0.427-0.839$ \\
\hline Fusion surgery & $<0.001$ & 1.917 & $1.356-2.709$ \\
\hline History of DVT & 0.035 & 1.697 & $1.038-2.776$ \\
\hline
\end{tabular}

(median 6.8 days vs 3.6 days; HR 0.6847 , log-rank $\mathrm{p}=$ 0.0003).

The cumulative incidence of VTEs was strongly correlated with the postoperative day in both groups (Spear$\operatorname{man} \mathrm{r}=0.9746,95 \%$ CI 0.9457-0.9883, and $\mathrm{p}<0.0001$ for the chemoprophylaxis group; Spearman $\mathrm{r}=0.9061$, 95\% CI $0.8065-0.9557$, and $\mathrm{p}<0.0001$ for the nonchemoprophylaxis group) (Fig. 1). The cumulative incidence of VTE was lower in the chemoprophylaxis group than the nonchemoprophylaxis group throughout the 30-day postoperative period. Notably, a larger proportion of patients receiving chemoprophylaxis (493 patients [25.89\%]) underwent venous duplex ultrasonography compared with the nonchemoprophylaxis group (409 patients [8.24\%]).

By inspection, the cumulative incidence of VTEs increased significantly in both groups in the first 2 postoperative weeks and then plateaued. Linear regression was therefore performed to separately assess the first 2 postoperative weeks and the remainder of the 30-day postoperative period. Cumulative VTE incidence and the postoperative day were strongly linearly correlated in the first 2 postoperative weeks $(\mathrm{R}=0.9396$ and $\mathrm{p}<0.0001$ for the chemoprophylaxis group; $\mathrm{R}=0.8190$ and $\mathrm{p}=0.0003$ for the nonchemoprophylaxis group). Additionally, the cu- 


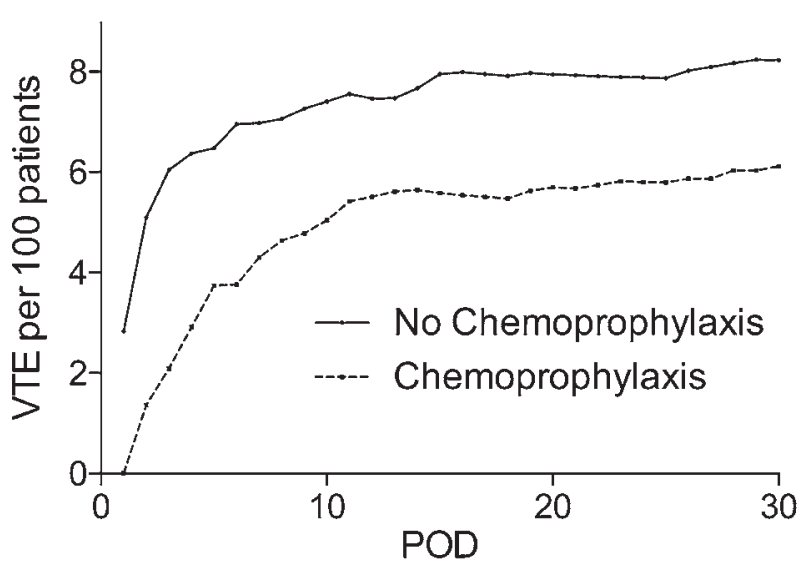

FIG. 1. The cumulative incidence of VTEs by postoperative day. Spearman $r=0.9746,95 \% \mathrm{Cl} 0.9457-0.9883$, and $p<0.0001$ for the chemoprophylaxis group, and Spearman $r=0.9061,95 \% \mathrm{Cl} 0.8065-0.9557$, and $p<0.0001$ for the nonchemoprophylaxis group. POD = postoperative day.

mulative incidence of VTE was linearly correlated with the remainder of the 30-day postoperative period $(\mathrm{R}=$ 0.9535 and $\mathrm{p}<0.0001$ for the chemoprophylaxis group; $\mathrm{R}=0.6562$ and $\mathrm{p}=0.0058$ for the nonchemoprophylaxis group). Moreover, for both groups, the strong linear relationships between the cumulative incidence of VTEs and postoperative day were significantly different between the first 2 postoperative weeks and the remainder of the postoperative period ( $\mathrm{p}<0.0001$ for both groups) (Fig. 2). Furthermore, the regression lines showed a significantly higher cumulative incidence of VTEs in the nonchemoprophylaxis group in both the first 2 postoperative weeks $(\mathrm{p}=0.0475)$ and the remainder of the 30-day postoperative period ( $\mathrm{p}=0.0011)$ (Fig. 3).

For the first 2 postoperative weeks, the cumulative incidence of VTEs by postoperative day is ([0.3923 $\times$ postoperative day $]+0.9728)(\mathrm{p}<0.0001, \mathrm{R}=0.93957)$ for the chemoprophylaxis group and $([0.2545 \times$ postoperative day +4.709$)(p=0.0003, R=0.81896)$ for the nonchemoprophylaxis group. For the remainder of the 30-day postoperative period, the cumulative incidence of VTEs by postoperative day is $([0.03885 \times$ postoperative day $]+$
4.887) $(\mathrm{p}<0.0001, \mathrm{R}=0.9535)$ for the chemoprophylaxis group and $([0.01667 \times$ postoperative day $]+7.624)(\mathrm{p}=$ $0.0058, R=0.6562$ ) for the nonchemoprophylaxis group. The trend lines for the cumulative incidence of VTEs were significantly different during the first 2 postoperative weeks $(\mathrm{p}=0.0475)$ and the remainder of the 30 -day postoperative period $(\mathrm{p}=0.0011)$.

There was no statistically significant relationship between the prevalence of VTEs and postoperative day in either the chemoprophylaxis group (Spearman $\mathrm{r}=0.09513$; $\mathrm{p}=0.6171)$ (Fig. 4) or the nonchemoprophylaxis group (Spearman $r=0.1265 ; p=0.5054)$; therefore, the prevalence of VTEs could not be determined as a function of the postoperative day.

\section{Discussion}

VTE after spine surgery is a major complication. We identified 5 clinical selection factors that predicted using chemoprophylaxis against VTEs. Our data show that the cumulative incidence of VTEs rises in a linear fashion in the first 2 postoperative weeks and then plateaus. Chemoprophylaxis patients reached their plateau point at a lower cumulative incidence than nonchemoprophylaxis patients. At no point in the 30-day postoperative period was the cumulative incidence of VTEs higher in the chemoprophylaxis group than the nonchemoprophylaxis group. Moreover, VTEs occurred 3.2 days later in patients who received chemoprophylaxis than patients who do not. The proportion and timing of epidural hematomas were equivalent on both groups.

Our observed rate of symptomatic VTEs is consistent with that in the current literature. A recent systematic review of 25 separate series showed an overall VTE rate of $2.1 \%$ in spine surgery patients,,${ }^{10,11}$ which is comparable to our rate of 2.5\%. Notably, however, significant methods of detecting VTEs vary significantly between series, leading to a wide variance in the 30-day VTE rates ranging from $0.3 \%$ to $31 \%{ }^{8,11,15,17,28}$ In particular, studies citing rates of asymptomatic DVT after spinal surgery often report high rates, ${ }^{17,20}$ but studies involving administrative databases often quote much lower rates. ${ }^{12,21}$ Compared with studies evaluating symptomatic VTEs, our results appear consistent.
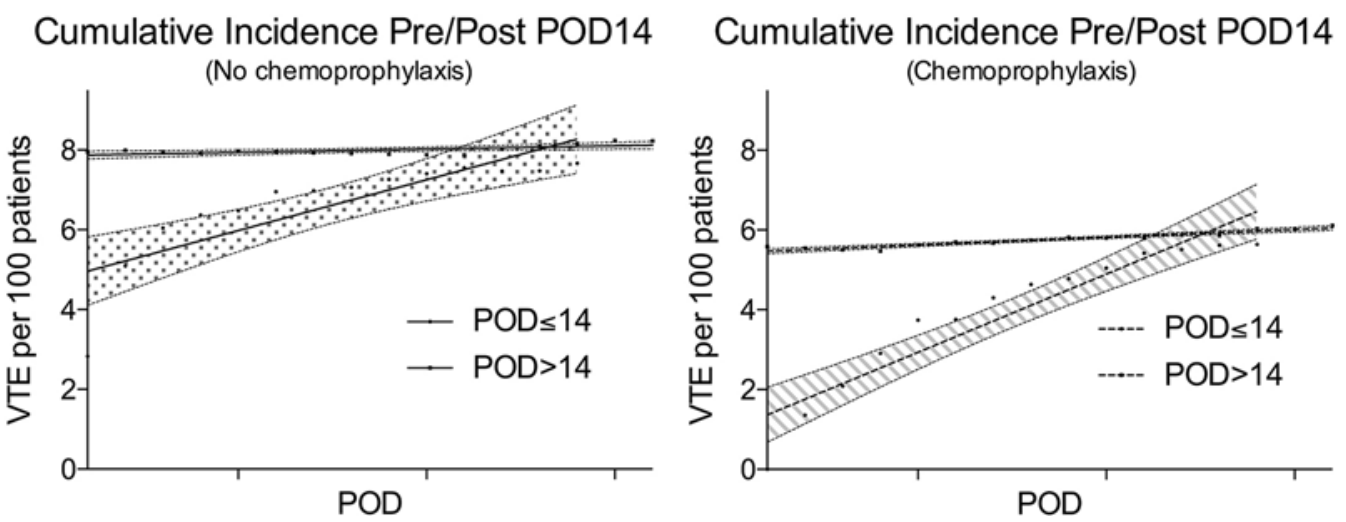

FIG. 2. The linear relationship between POD and the cumulative incidence of VTEs differed significantly when the first 14 postoperative days were compared to the remainder of the 30 -day postoperative period ( $p<0.0001$ for both groups). 

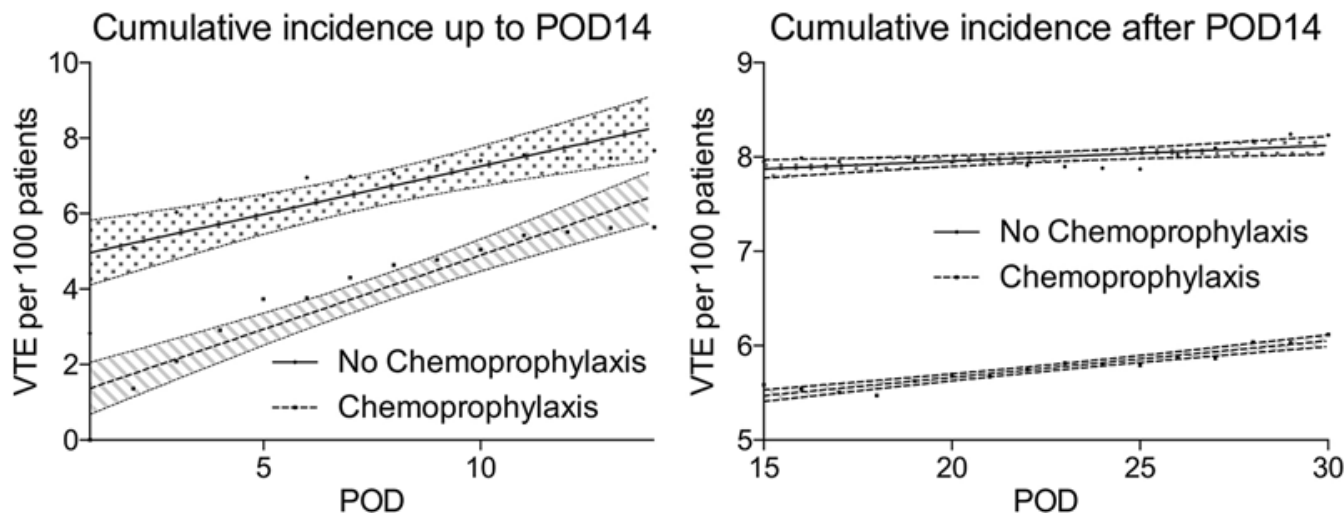

FIG. 3. The cumulative incidence of VTEs was significantly higher in the nonchemoprophylaxis group for both the first 2 postoperative weeks $(p=0.0475)$ and the remainder of the 30 -day postoperative period $(p=0.0011)$.

Our study paradoxically reported higher rates of VTEs in those patients who received pharmacological prophylaxis $(3.62 \%)$ compared with patients in the nonchemoprophylaxis group (2.03\%). However, it should be noted that there was a significant selection effect in sorting the chemoprophylaxis and nonchemoprophylaxis groups. Indeed, age, ${ }^{24,27}$ history of DVT, ${ }^{16}$ prolonged surgery, ${ }^{16,19,21}$ and fusion surgery predicted selection for chemoprophylaxis $^{9}$ and are all known to be associated with VTE after spine surgery. Moreover, the median length of stay of the chemoprophylaxis group was 5 times longer than that for the nonchemoprophylaxis group; this is a known risk factor for $\mathrm{VTE},{ }^{21}$ possibly due to prolonged immobility and greater opportunity for VTEs. To account for the difference in the length of stay between the chemoprophylaxis and nonchemoprophylaxis groups, we calculated the cumulative incidence rather than the standard incidence or prevalence. Cumulative incidence counts all VTEs up to a given postoperative day, which is normalized by the number of days during which those VTEs could have been counted. The y-axis of Fig. 1 indicates that the number of VTEs per inpatient hospital day in the chemoprophylaxis group was lower than in the nonchemoprophylaxis group.

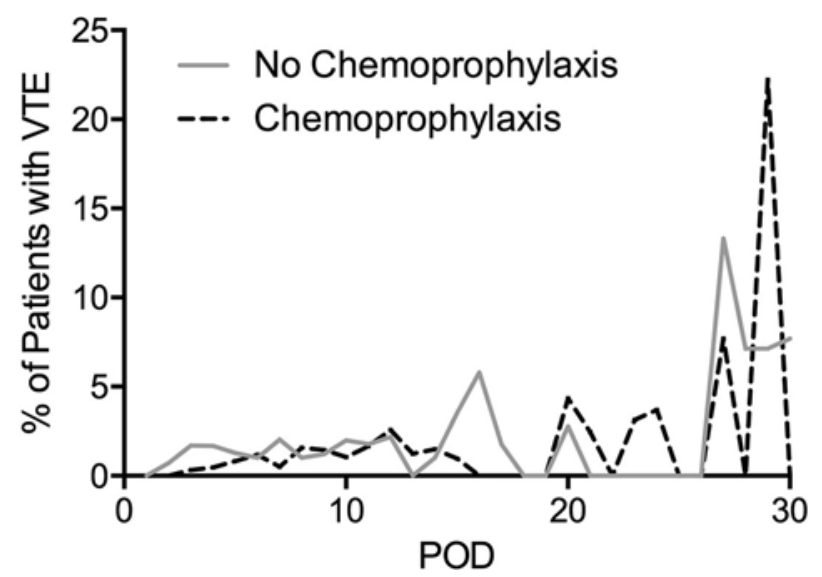

FIG. 4. The prevalence of VTEs by POD. There was no relationship between the prevalence of VTEs and POD for either the chemoprophylaxis group (Spearman $r=0.09513 ; p=0.6171$ ) or the nonchemoprophylaxis group (Spearman $r=0.1265 ; p=0.5054)$.
However, as noted in our study, the chemoprophylaxis group had a median length of stay that was 5 times longer than the nonchemoprophylaxis group. If the per-day risks of VTEs were equal between the chemoprophylaxis group and nonchemoprophylaxis group, a 5-fold increase in length of stay in the chemoprophylaxis patients would be expected to lead to a 5-fold increase in VTEs compared with the nonchemoprophylaxis patients. While there were more VTEs overall in the chemoprophylaxis group (3.62\% vs $2.03 \%, \mathrm{p}<0.001)$, the cumulative incidence of VTEs was actually lower among chemoprophylaxis patients throughout the entire 30-day postoperative period, as indicated in Fig. 1. We believe that this is evidence that chemoprophylactic anticoagulation reduces VTEs. Indeed, our finding that the cumulative incidence of VTEs was actually lower in the chemoprophylaxis group for the 30-day postoperative period, despite more overall VTEs, suggests that chemoprophylaxis successfully reduced VTEs within this relatively high-risk population. Furthermore, as demonstrated in Fig. 1, the cumulative incidence of VTEs rose within the first 2 postoperative weeks before plateauing for the remainder of the 30-day postoperative period, but the chemoprophylaxis patients reached their plateau point at a lower cumulative incidence than the nonchemoprophylaxis patients.

Our finding that the time-to-event for VTE was delayed in patients receiving chemoprophylaxis is consistent with existing literature. McClendon et al. similarly found that chemoprophylactic anticoagulation delayed time to VTE following spine surgery. ${ }^{16}$ Moreover, our observed median time-to-event data-specifically 6.8 days for chemoprophylaxis patients versus 3.6 days for nonchemoprophylaxis patients -is consistent with existing studies. Existing spine surgery series note an average time to VTE occurrence of postoperative Day $5,{ }^{1,18}$ although other series have reported the average time to VTE as late as postoperative Day $15 .{ }^{16}$ Of note, differences in reporting methods, including reporting mean versus median time-to-event data, may contribute to the variability observed between these studies.

Our study builds on the existing literature by assessing the cumulative incidence of VTEs by postoperative day. The strong linear relationship $(\mathrm{R}>0.80)$ we observed between the cumulative incidence of VTEs and postoperative day suggests a predictable increase in risk of VTE 
for each inpatient postoperative day, followed by a plateau after the second postoperative week. Equally, our finding that the cumulative incidence of VTEs in the chemoprophylaxis group was significantly lower than that of the nonchemoprophylaxis group supports the use of a chemoprophylactic anticoagulant in preventing VTEs. To the best of our knowledge, our study is the first in the literature to perform such an analysis of VTEs after spine surgery.

Our study has important limitations. It was conducted retrospectively, a study design that is known to be limited by information bias. It was performed at a single institution, and therefore reflects the judgment of only our clinicians with respect to patient selection and management. Patient populations receiving prophylactic VTE treatment may differ elsewhere, as there is currently wide variability in practice regarding which spine surgery patients should receive chemoprophylaxis. ${ }^{10}$ However, this also suggests that there may be less variability in the decision to give chemoprophylaxis in our single-center study compared with a multicenter study. In addition, due to the lack of an institution-wide DVT screening protocol at our institution, the incidence of VTEs reflects only the patients who were diagnosed with DVT and pulmonary embolisms. As a result, the true incidence of VTEs may have been higher because subclinical VTEs may have been missed. Because there is no great evidence of the clinical consequence of missed subclinical VTEs, we believe this limitation is understandable given the cost and lack of evidence behind universal DVT screening. The finding that a larger proportion of patients who received chemoprophylaxis underwent venous duplex ultrasonography compared with the nonchemoprophylaxis group suggests that providers may be more likely to perform venous duplex ultrasonography in patients who they believe are at a higher risk of developing such complications, or providers have a lower threshold for obtaining these scans in this higher risk population.

The next steps include defining VTE risks and the efficacy of prophylactic treatment on a prospective basis. Such studies could be conducted on a multiinstitutional scale to further incorporate institutional variations in decision management in various different regions. Secondly, randomized controlled trials may be necessary to further elucidate the desired treatment thresholds for deciding which patients should receive VTE prophylaxis after spinal surgery.

\section{Conclusions}

VTEs remain significantly dangerous adverse events of postsurgical recovery and contribute to a great deal of morbidity in recovering patients. The addition of pharmacological prophylaxis is effective in prolonging VTE development in high-risk patients. Likewise, the cumulative incidence of VTEs after spinal surgery rises steadily within the first 2 weeks postoperatively and is thereafter highly dependent on hospital length of stay.

\section{References}

1. Akeda K, Matsunaga H, Imanishi T, Hasegawa M, Sakakibara T, Kasai Y, et al: Prevalence and countermeasures for venous thromboembolic diseases associated with spinal surgery: a follow-up study of an institutional protocol in 209 patients. Spine (Phila Pa 1976) 39:791-797, 2014

2. Anderson FA Jr, Spencer FA: Risk factors for venous thromboembolism. Circulation 107 (23 Suppl 1):I9-I16, 2003

3. Brambilla S, Ruosi C, La Maida GA, Caserta S: Prevention of venous thromboembolism in spinal surgery. European Spine J 13:1-8, 2004

4. Cheng JS, Arnold PM, Anderson PA, Fischer D, Dettori JR: Anticoagulation risk in spine surgery. Spine (Phila Pa 1976) 35 (9 Suppl):S117-S124, 2010

5. Cho KJ, Suk SI, Park SR, Kim JH, Kim SS, Choi WK, et al: Complications in posterior fusion and instrumentation for degenerative lumbar scoliosis. Spine (Phila Pa 1976) 32:2232-2237, 2007

6. De Martino RR, Wallaert JB, Rossi AP, Zbehlik AJ, Suckow B, Walsh DB: A meta-analysis of anticoagulation for calf deep venous thrombosis. J Vasc Surg 56:228-237, 237.e1, 2012

7. Deyo RA, Mirza SK, Martin BI, Kreuter W, Goodman DC, Jarvik JG: Trends, major medical complications, and charges associated with surgery for lumbar spinal stenosis in older adults. JAMA 303:1259-1265, 2010

8. Fang MC, Maselli J, Lurie JD, Lindenauer PK, Pekow PS, Auerbach AD: Use and outcomes of venous thromboembolism prophylaxis after spinal fusion surgery. J Thromb Haemost 9:1318-1325, 2011

9. Fineberg SJ, Oglesby M, Patel AA, Pelton MA, Singh K: The incidence and mortality of thromboembolic events in lumbar spine surgery. Spine (Phila Pa 1976) 38:1154-1159, 2013

10. Glotzbecker MP, Bono CM, Harris MB, Brick G, Heary RF, Wood KB: Surgeon practices regarding postoperative thromboembolic prophylaxis after high-risk spinal surgery. Spine (Phila Pa 1976) 33:2915-2921, 2008

11. Glotzbecker MP, Bono CM, Wood KB, Harris MB: Thromboembolic disease in spinal surgery: a systematic review. Spine (Phila Pa 1976) 34:291-303, 2009

12. Goz V, McCarthy I, Weinreb JH, Dallas K, Bendo JA, Lafage $\mathrm{V}$, et al: Venous thromboembolic events after spinal fusion: which patients are at high risk? J Bone Joint Surg Am 96:936-942, 2014

13. Gray DT, Deyo RA, Kreuter W, Mirza SK, Heagerty PJ, Comstock BA, et al: Population-based trends in volumes and rates of ambulatory lumbar spine surgery. Spine (Phila Pa 1976) 31:1957-1964, 2006

14. Hansson PO, Sörbo J, Eriksson H: Recurrent venous thromboembolism after deep vein thrombosis: incidence and risk factors. Arch Intern Med 160:769-774, 2000

15. Maung AA, Schuster KM, Kaplan LJ, Maerz LL, Davis KA: Risk of venous thromboembolism after spinal cord injury: not all levels are the same. J Trauma 71:1241-1245, 2011

16. McClendon J, Smith TR, O'Shaughnessy BA, Sugrue PA, Thompson SE, Koski TR: Time to event analysis for the development of venous thromboembolism after spinal fusion $\geq$ 5 levels. World Neurosurg 84:826-833, 2015

17. Oda T, Fuji T, Kato Y, Fujita S, Kanemitsu N: Deep venous thrombosis after posterior spinal surgery. Spine (Phila Pa 1976) 25:2962-2967, 2000

18. Pateder DB, Gonzales RA, Kebaish KM, Antezana DF, Cohen DB, Chang JY, et al: Pulmonary embolism after adult spinal deformity surgery. Spine (Phila Pa 1976) 33:301-305, 2008

19. Piper K, Algattas H, DeAndrea-Lazarus IA, Kimmell KT, Li YM, Walter KA, et al: Risk factors associated with venous thromboembolism in patients undergoing spine surgery. $\mathbf{J}$ Neurosurg Spine 26:90-96, 2016

20. Sansone JM, del Rio AM, Anderson PA: The prevalence of and specific risk factors for venous thromboembolic disease following elective spine surgery. J Bone Joint Surg Am 92:304-313, 2010 
21. Sebastian AS, Currier BL, Kakar S, Nguyen EC, Wagie AE, Habermann ES, et al: Risk factors for venous thromboembolism following thoracolumbar surgery: analysis of 43,777 patients from the American College of Surgeons National Surgical Quality Improvement Program 2005 to 2012. Global Spine J 6:738-743, 2016

22. Thromboembolic Risk Factors (THRIFT) Consensus Group: Risk of and prophylaxis for venous thromboembolism in hospital patients. BMJ 305:567-574, 1992

23. Tzoran I, Saharov G, Brenner B, Delsart D, Román P, Visoná A, et al: Silent pulmonary embolism in patients with proximal deep vein thrombosis in the lower limbs. J Thromb Haemost 10:564-571, 2012

24. Verla T, Adogwa O, Toche U, Farber SH, Petraglia F, Murphy $\mathrm{KR}$, et al: Impact of increasing age on outcomes of spinal fusion in adult idiopathic scoliosis. World Neurosurg 87:591597, 2016

25. Watson N: Venous thrombosis and pulmonary embolism in spinal cord injury. Paraplegia 6:113-121, 1968

26. Xing KH, Morrison G, Lim W, Douketis J, Odueyungbo A, Crowther M: Has the incidence of deep vein thrombosis in patients undergoing total hip/knee arthroplasty changed over time? A systematic review of randomized controlled trials. Thromb Res 123:24-34, 2008

27. Yang SD, Liu H, Sun YP, Yang DL, Shen Y, Feng SQ, et al: Prevalence and risk factors of deep vein thrombosis in patients after spine surgery: a retrospective case-cohort study. Sci Rep 5:11834, 2015

28. Yoshioka K, Murakami H, Demura S, Kato S, Tsuchiya H: Prevalence and risk factors for development of venous throm- boembolism after degenerative spinal surgery. Spine (Phila Pa 1976) 40:E301-E306, 2015

29. Zar JH: Biostatistical Analysis, ed 2. Englewood Cliffs, NJ: Prentice-Hall, 1984

30. Zhou X, Qian W, Li J, Zhang P, Yang Z, Chen W, et al: Who are at risk for thromboembolism after arthroplasty? A systematic review and meta-analysis. Thromb Res 132:531536,2013

\section{Disclosures}

The authors report no conflict of interest concerning the materials or methods used in this study or the findings specified in this paper.

\section{Author Contributions}

Conception and design: Dahdaleh, Dhillon. Acquisition of data: Hopkins, Dhillon. Analysis and interpretation of data: Cloney, Hopkins. Drafting the article: all authors. Critically revising the article: all authors. Reviewed submitted version of manuscript: all authors. Approved the final version of the manuscript on behalf of all authors: Dahdaleh. Statistical analysis: Cloney. Study supervision: Dahdaleh.

\section{Correspondence}

Nader Dahdaleh, NMH/Arkes Family Pavilion, Ste. 2210, 676 N Saint Clair, Chicago, IL 60611. email: nader.dahdaleh@ northwestern.edu. 